\title{
Bovine tracheal responsiveness in vitro: role of the epithelium and nitric oxide
}

\author{
G. Sadeghi-Hashjin*\#, P.A.J. Henricks*, G. Folkerts*, \\ A.K.C.P. Verheyen**, H.J. van der Linde*, F.P. Nijkamp*
}

Bovine tracheal responsiveness in vitro: role of the epithelium and nitric oxide. G. Sadeghi-Hashjin, P.A.J. Henricks, G. Folkerts, A.K.C.P. Verheyen, H.J. van der Linde, F.P. Nijkamp. @ ERS Journals Ltd 1996.

ABSTRACT: Airway epithelium releases inhibitory factors, such as nitric oxide (NO) and prostaglandin $\mathrm{E}_{2}\left(\mathrm{PGE}_{2}\right)$, which may counteract bronchoconstriction. We investigated whether epithelium-derived inhibitory substances exert a crucial influence on bovine tracheal responsiveness in vitro.

Isotonic and isometric contractions in response to histamine of intact and epithelium-denuded tracheal smooth muscle strips were compared. In addition, the effects of $\mathrm{L}$-arginine (L-arg), $\mathrm{N}^{\mathrm{G}}$-nitro-L-arginine methyl esther (L-NAME), and $\mathrm{N}^{\mathrm{G}}$ monomethyl L-arginine (L-NMMA) on histamine responsiveness were investigated. The release of $\mathrm{NO}$ and $\mathrm{PGE}_{2}$ from tracheal epithelium was measured.

Removal of the epithelium from tracheal smooth muscle strips did not change the negative log of the concentration of histamine producing half the maximal effect $\left(\mathrm{pD}_{2}\right)$ or the maximal effect $\left(E_{\max }\right)$. Incubation of the tissues for $25 \mathrm{~min}$ with $\mathrm{L}$-arg or L-NAME did not influence basal tone or the contractions induced by histamine. However, incubation with L-NMMA increased the basal tone and caused a slight hyporesponsiveness to histamine. S-nitroso-N-acetyl-penicillamine (SNAP, a direct NO donor) reversed the contraction induced by histamine in a concentration-dependent manner. Stimulation of the epithelial layer by $0.1 \mu \mathrm{M}$ histamine increased the release of NO 3-4 fold compared to basal levels; this effect was completely inhibited in the presence of L-NMMA. In addition, $1 \mathrm{mM}$ histamine caused a significant increase in the release of $\mathrm{PGE}_{2}$ from the epithelial tissue.

In conclusion, no functional inhibitory influence of the epithelium can be identified in bovine airways. The $\mathrm{S}$-nitroso- $\mathrm{N}$-acetyl-penicillamine-induced relaxation demonstrates the presence of a nitric oxide sensitive pathway in bovine airways. However, the amounts of nitric oxide and prostaglandin $E_{2}$ released from bovine tracheal epithelium are probably too low to exert a significant effect on the histamine-induced contractions.

Eur Respir J., 1996, 9, 2286-2293.
*Dept of Pharmacology, Utrecht Institute for Pharmaceutical Sciences, Utrecht University, Utrecht, The Netherlands. **Dept of Cardiovascular and Pulmonary Pharmacology, Janssen Research Foundation, Beerse, Belgium. \#Present address: Dept of Basic Sciences, Faculty of Veterinary Medicine, Urmia University, P.O. Box 165, Urmia 57153, I.R. Iran.

Correspondence: P.A.J. Henricks Dept of Pharmacology

Utrecht Institute for Pharmaceutical Sciences Utrecht University

P.O. Box 80082

3508 TB Utrecht

The Netherlands

Keywords: Airway epithelium airway responsiveness

bovine trachea

nitric oxide

prostaglandin $\mathrm{E}_{2}$

Received: February 231996

Accepted after revision July 201996
The airway epithelium acts as a protective barrier for the underlying airway smooth muscle against noxious substances, and it can release inhibitory factor(s), such as nitric oxide $(\mathrm{NO})$ and prostaglandin $\mathrm{E}_{2}\left(\mathrm{PGE}_{2}\right)$, to counteract excessive contractions of smooth muscle [15]. In some animal species, removal of the epithelium causes an increase in sensitivity of tracheal smooth muscle to histamine [5-8].

NO may have an important regulatory role in pulmonary function and the pathology of several lung diseases $[9,10]$. The constitutive isoform of NO synthase (cNOS) is activated by an increase of intracellular calcium and produces small amounts of NO which, in turn, activates guanylate cyclase, increases cyclic guanosine monophosphate (cGMP) and relaxes smooth muscle. NOS can be competitively blocked by $\mathrm{NG}^{\mathrm{G}}$-monomethylL-arginine (L-NMMA) and $\mathrm{NG}^{\mathrm{G}}$-nitro-L-arginine methyl esther (L-NAME) [11]. NO accounts for a part of the inhibitory nonadrenergic noncholinergic (NANC) responses in the guinea-pig, cat, pig and human airways in vitro [12-17]. NO has been shown to be released from guinea-pig tracheal epithelium upon stimulation by histamine [18]. Indeed, inhibition of the cNOS or direct inactivation of $\mathrm{NO}$ by superoxide anion induces airway hyperresponsiveness to histamine in guinea-pigs $[19,20]$.

The present study was performed to examine the influence of epithelium as well as endogenous and exogenous NO on the airway reactivity of bovine isolated tracheal smooth muscle. The histamine-induced isometric and isotonic contractions of intact and epithelium-denuded strips of bovine tracheal smooth muscle were measured. Effects of L-arginine (L-arg), L-NAME and L-NMMA on the basal tension, as well as on the responsiveness to histamine, of the smooth muscle were also investigated. Furthermore, the histamine-induced release of NO and $\mathrm{PGE}_{2}$ from tracheal epithelium was measured. 


\section{Materials and methods}

\section{Animals and preparation of smooth muscle strips}

Macroscopically normal tracheas were obtained from young cattle (1-2 yrs of age) of either sex directly after they were slaughtered in a local abattoir. The upper thirds of the tracheas were placed in Krebs bicarbonate buffer that had been pre-aerated with a mixture of oxygen $(95 \%)$ and $\mathrm{CO}_{2}(5 \%)$. The tissues were kept in buffer at room temperature during transportation, and were brought to the laboratory within $1 \mathrm{~h}$ and studied the same day.

Preparation of smooth muscle strips was performed as described previously [21]. Briefly, a piece of tracheal smooth muscle, attached to the terminal segments of cartilage rings, was fixed on a dissection board. The support of the rings prevented the possible rupture of muscle fibres and ensured their similar length throughout the preparation. By means of a template containing up to eight surgical blades (No. 22-4), 2-7 strips of about $20 \mathrm{~mm}$ length $\times 2.5 \mathrm{~mm}$ width were incised parallel to the direction of muscle fibres, while the ends of the strips were still connected to the whole piece of tissue. At this stage, when required, the epithelial and submucosal layers were easily removed by means of a surgical blade, without any physical stretch on the strips. A small ruler $(1 \times 5 \mathrm{~cm})$ was inserted under the strips and they were then tied precisely on either side so that the strips were $1 \mathrm{~cm}$ long. Each piece of silk string had a ring knot for connecting the strips to the tissue chamber and to the transducer. The strips were cut by means of scissors about $2 \mathrm{~mm}$ outside the knots.

\section{Histology}

Intact and epithelium-denuded tracheal smooth muscle strips were fixed in phosphate-buffered formaldehyde $(10 \%)$ and embedded in paraffin blocks. Sections measuring $5 \mu \mathrm{m}$ were stained with haematoxylin and eosin and were evaluated by light microscopy.

\section{Measurement of contraction and relaxation}

Muscle strips were suspended in $12 \mathrm{~mL}$ organ baths containing Krebs bicarbonate solution at $37^{\circ} \mathrm{C}$, for isotonic or isometric recording (Harvard Bioscience, Kent, UK). Krebs bicarbonate buffer was continuously aerated with $5 \% \mathrm{CO}_{2}$ in $\mathrm{O}_{2}$. The strips were kept under an optimal preload of $5 \mathrm{~g}$ [21]. The tissues were washed three times at 15 min intervals, after which a stable tone was reached. Only one concentration-response curve was constructed on a tissue segment. Transducers were connected to an analogue-digital convertor (Intelligent International PCI System, Burr Brown Co., Tucson, AZ, USA) integrating the organ baths in a semiautomatic set-up. This allowed continuous sampling, on-line equilibrium detection and real-time display of the responses on a computer screen of up to 12 organ baths.
Effect of removal of the epithelium on tracheal responsiveness

Intact and epithelium-denuded bovine tracheal smooth muscle strips were mounted in the organ baths and concentration-response curves to histamine were obtained under isotonic and isometric conditions.

\section{Modulation of histamine concentration-response curves by endogenous $\mathrm{NO}$}

Intact tracheal smooth muscle strips were preincubated with $1 \mathrm{mM}$ L-arg, $120 \mu \mathrm{M}$ L-NAME or $120 \mu \mathrm{M}$ L-NMMA for $25 \mathrm{~min}$, after which histamine concentration-response curves $(10 \mathrm{nM}-1 \mathrm{mM})$ were constructed. Concentrations of L-arg, L-NAME and L-NMMA were chosen based on their effectiveness on the guinea-pig isolated trachea [19].

Sensitivity of bovine tracheal smooth muscle to the exogenous $N O$

Intact strips were first contracted with histamine (1 $\mathrm{mM}$ ) and, thereafter, were exposed to $\mathrm{L}-\arg (1 \mathrm{mM}$ for $10 \mathrm{~min}$ ) or to increasing concentrations of the NO donor S-nitroso-N-acetyl-penicillamine (SNAP), 0.1-100 $\mu \mathrm{M}$.

\section{Measurement of $\mathrm{NO}$ and $\mathrm{PGE}_{2}$}

The epithelial layer was removed from bovine isolated trachea. The epithelial tissue $(0.5 \mathrm{~g}$ in weight $)$ was suspended in $12 \mathrm{~mL}$ Krebs buffer at $37^{\circ} \mathrm{C}$. Tissues were incubated with medium, L-NMMA $(120 \mu \mathrm{M})$ or L-arg $(1 \mathrm{mM})$ for $25 \mathrm{~min}$ and, thereafter, stimulated with increasing concentrations of histamine $(0.1 \mu \mathrm{M}$ to $1 \mathrm{mM})$ for $5 \mathrm{~min}$ in each case. Samples were taken from Krebs buffer before and after incubation and after each stimulation of the epithelium.

NO was measured based on the conversion of nitrite in the buffer to NO, as described previously [22]. Krebs solution $(0.1 \mathrm{~mL})$ taken from the organ bath was injected into a gas-stripping apparatus containing $2 \mathrm{~mL}$ of a $1 \%$ solution of $\mathrm{NaI}$ in glacial acetic acid, connected to a Sievers 270B NO analyser (Boulder, CO, USA) with a sensitivity of $>10 \mathrm{pmol} \cdot \mathrm{mL}^{-1}$. The amount of NO was calculated as pmol. $\mathrm{mg}^{-1}$ wet weight of the tissue. To measure NO released from SNAP, $0.1 \mathrm{~mL}$ of Krebs solution containing $1 \mathrm{pM}$ to $100 \mu \mathrm{M}$ of this drug was injected into the apparatus.

In the medium-treated, histamine-stimulated tissues, the release of $\mathrm{PGE}_{2}$ was also measured by means of radioimmunoassay (RIA). The amount of $\mathrm{PGE}_{2}$ was expressed as $\mathrm{ng} \cdot \mathrm{mg}^{-1}$ wet weight of the tissue.

\section{Drugs and solutions}

Required concentrations of L-NMMA and SNAP (Wellcome, UK), L-NAME (Sigma), histamine dihydrochloride and aminophylline anhydrous (OPG Farma, 
Utrecht, The Netherlands) were prepared daily and diluted in buffer. The $\left[{ }^{3} \mathrm{H}\right]-\mathrm{PGE}_{2}$ (with a specific activity of 154.00 Ci.mmol-1) was from New England Nuclear (Boston, MA, USA). The antibody for $\mathrm{PGE}_{2}$ was kindly provided by J. Beetens of Janssen Pharmaceutica (Beerse, Belgium). Krebs bicarbonate buffer was of the following composition (mM): $\mathrm{NaCl} 118.1 ; \mathrm{KCI} 4.7 ; \mathrm{CaCl}_{2} 2.5$; $\mathrm{MgSO}_{4}$ 1.2; $\mathrm{NaHCO}_{3} 25.0 ; \mathrm{KH}_{2} \mathrm{PO}_{4} 1.2$; and glucose 8.3 .

\section{Statistics}

The parameters defining the maximal contraction induced by histamine $(E \max )$, as millimetres of displacement or milligrams of tension, and the negative logarithm of the molar concentration of histamine that gives a half maximal response $\left(\mathrm{pD}_{2}\right)$ were averaged for various experimental groups. The data were analysed first for normal distribution and then for statistical significance by oneway analysis of variance (ANOVA) and post-hoc Bonferroni's test, respectively. A p-value of less than 0.05 was considered to be significant. Values are expressed as mean \pm SEM.

\section{Results}

\section{Effect of epithelium removal}

Intact, pseudostratified columnar epithelium with its lamina propria and a submucosal layer was demonstrated in the preparations. These layers were completely removed in the skinned preparations without any apparent damage to the smooth muscle (fig. 1). Histamine induced concentration-dependent isotonic and isometric contractions of tracheal smooth muscle (fig. 2 ); no difference in the sensitivity to histamine was observed between the two methods. There was no significant difference in the sensitivity or maximal shortening to histamine between intact and epithelium-denuded preparations (table 1 and fig. 2). The histamine-contracted tissues relaxed to their initial tone after addition of aminophylline $(20 \mathrm{mM})$, without any significant difference between different groups (table 1).

\section{Modulation of histamine concentration-response curves} by endogenous $\mathrm{NO}$

L-Arg ( $1 \mathrm{mM}, \mathrm{n}=5)$ and L-NAME $(120 \mu \mathrm{M}, \mathrm{n}=5)$ had no effect on the basal length or the responsiveness of bovine tracheal smooth muscle to histamine (fig. 3a and $3 \mathrm{~b}$, respectively, and table 2). However, $120 \mu \mathrm{M} \mathrm{L}-$ NMMA $(n=6)$ contracted the strips during the preincubation period by $1.1 \pm 0.3 \mathrm{~mm}(\mathrm{p}<0.05)$ and shifted the histamine concentration-response curve downwards (fig. $3 \mathrm{c})$. The maximal shortening was decreased by $18 \%$ from $5.5 \pm 0.3 \mathrm{~mm}$ in the control group to $4.5 \pm 0.4 \mathrm{~mm}$ in the L-NMMA-treated group. There was no difference in the $\mathrm{pD}_{2}$ values between the groups (fig. $3 \mathrm{c}$ and table 2).

In a separate experiment, it was found that the contractile effect of L-NMMA on the muscle strips was a)

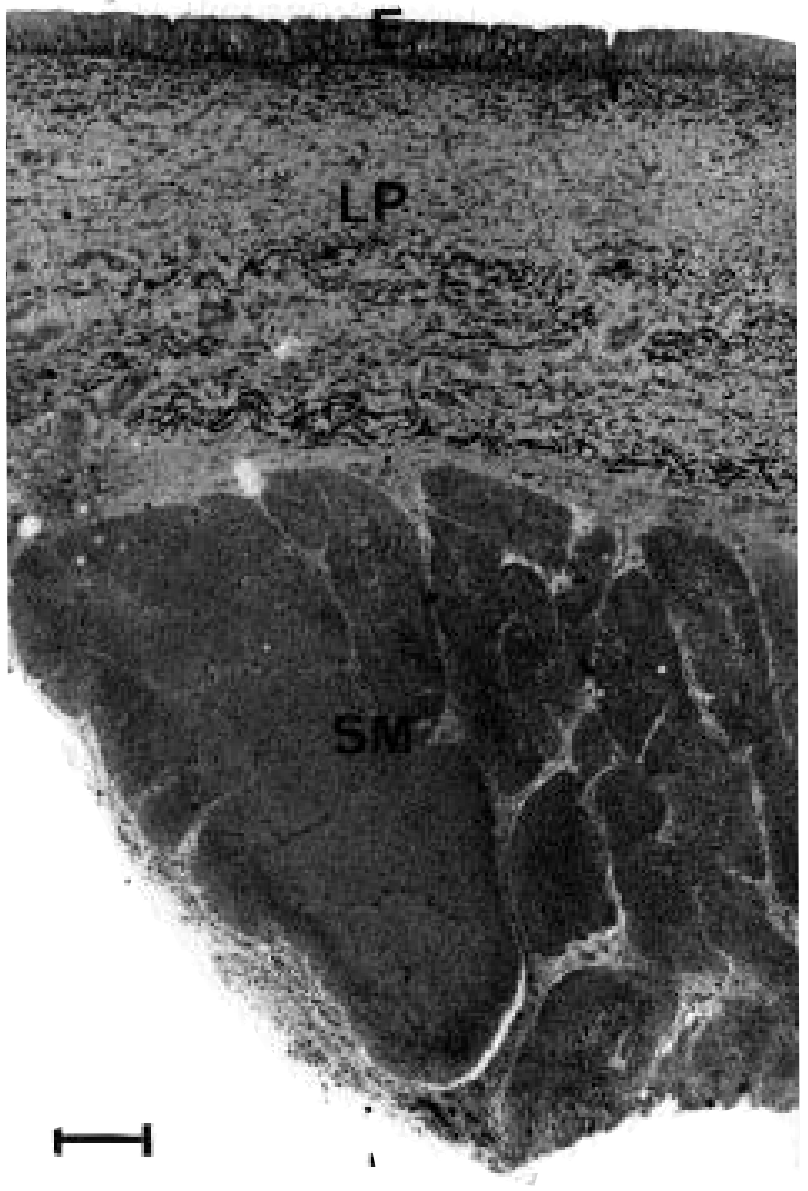

b)

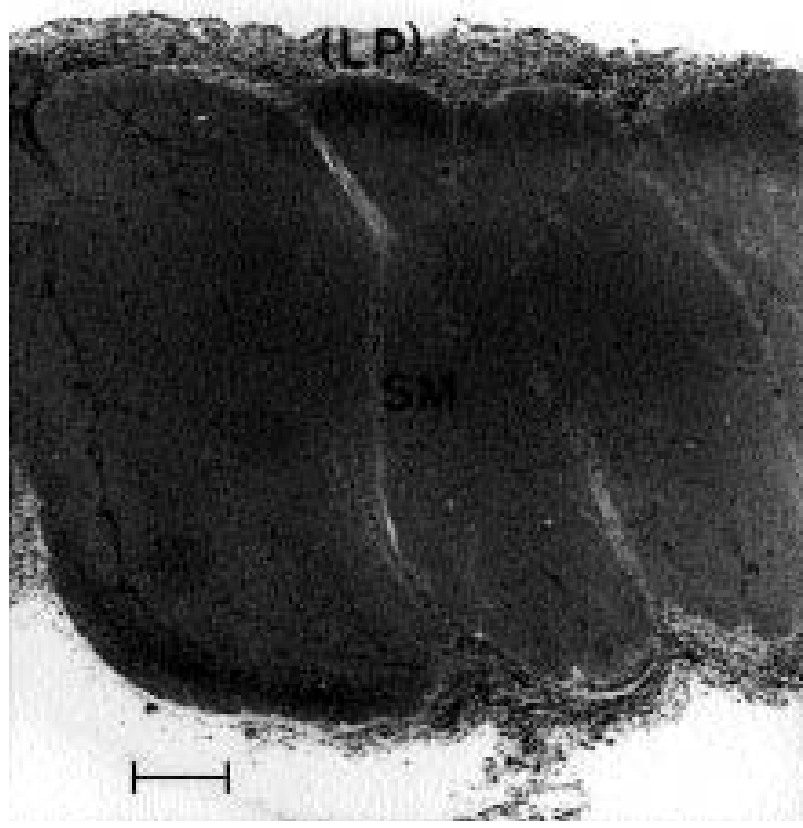

Fig. 1. - Photomicrographs of bovine tracheal smooth muscle strips: a) before; and b) after removal of epithelial and submucosal layers. In the first figure, the normal epithelium (E) with underlying lamina propria (LP) and inherent smooth muscle layer (SM) is shown. After the procedure, the epithelium is completely absent; only a small remnant of the lamina propria with the intact associated smooth muscle is seen. (Internal scale bar $=200 \mu \mathrm{m}$ ). 

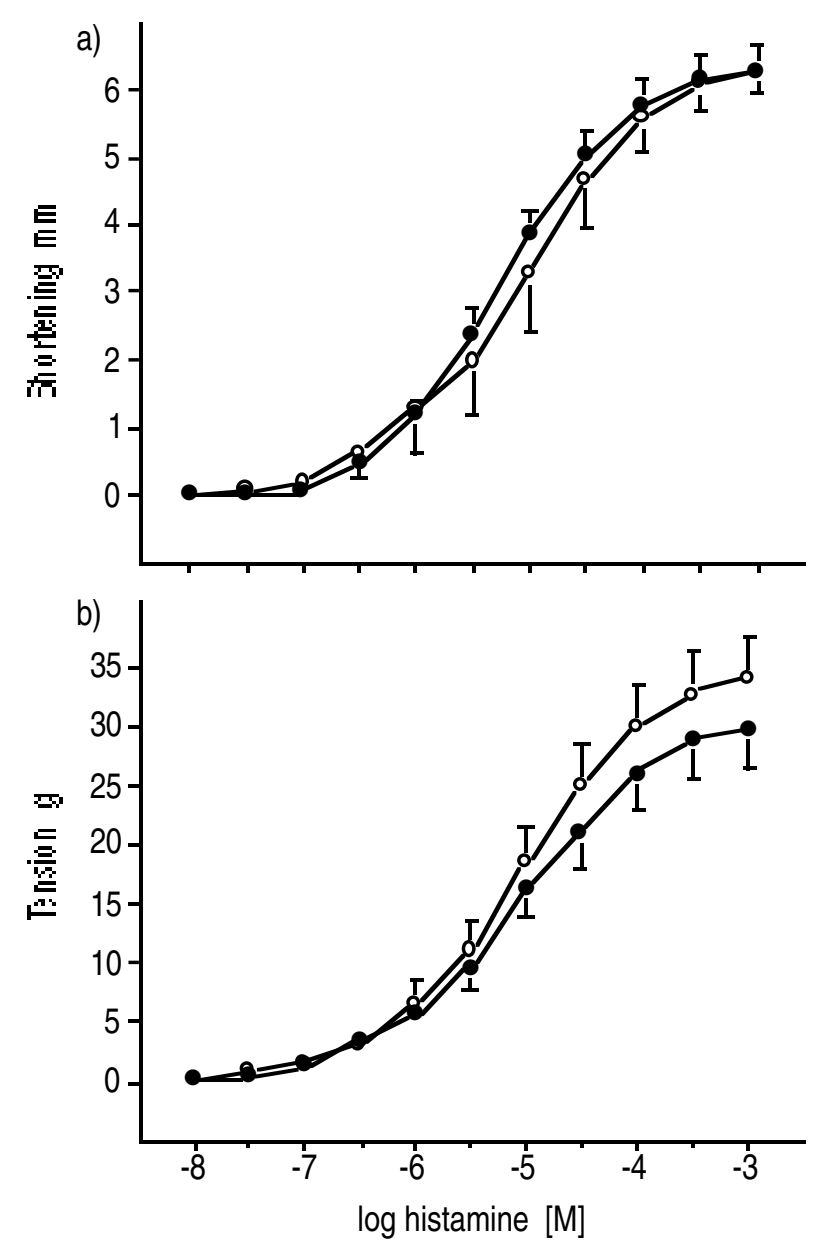

Fig. 2. - Histamine concentration-response curves of bovine isolated, intact (—- - ) and epithelium-denuded (- - ) tracheal smooth muscle strips. Removal of epithelium changed neither: a) the isotonic $(\mathrm{n}=12)$; nor $\mathrm{b})$ the isometric $(\mathrm{n}=5)$ contractions induced by histamine. Results are presented as mean \pm SEM.

not NO-dependent because preincubation with L-arg (1 $\mathrm{mM}$ for $25 \mathrm{~min}$ ) did not prevent the effect of $120 \mu \mathrm{M}$ L-NMMA; the tissues were contracted by $0.9 \pm 0.3 \mathrm{~mm}$ and $0.8 \pm 0.2 \mathrm{~mm}$ in the absence and presence of $\mathrm{L}-\mathrm{arg}$, respectively $(\mathrm{n}=6)$.

Table 1. - Parameters derived from histamine concentration-response curves of bovine isolated tracheal smooth muscle strips, with and without adherent epithelium, measured isotonically and isometrically

\begin{tabular}{lcc}
\hline & $\begin{array}{c}\text { Isotonic } \\
(\mathrm{n}=12)\end{array}$ & $\begin{array}{c}\text { Isometric } \\
(\mathrm{n}=5)\end{array}$ \\
\hline Emax \% & & \\
$\quad$ Intact & $100 \pm 6$ & $100 \pm 10$ \\
$\quad$ Epithelium-denuded & $94 \pm 4$ & $87 \pm 10$ \\
$\mathrm{pD}_{2}$ & & \\
$\quad$ Intact & $5.2 \pm 0.2$ & $5.1 \pm 0.1$ \\
$\quad$ Epithelium-denuded & $5.4 \pm 0.1$ & $5.1 \pm 0.1$ \\
Aminophylline relaxation & $\%+$ \\
$\quad$ Intact & $102 \pm 1$ & $108 \pm 1$ \\
$\quad$ Epithelium-denuded & $101 \pm 0.3$ & $110 \pm 5$ \\
\hline
\end{tabular}

Values are presented as mean \pm SEM. Emax: maximum tracheal shortening or tension induced by histamine; $\mathrm{pD}_{2}$ : negative $\log _{10}$ of the molar concentration of histamine giving $50 \%$ of Emax. and expressed as percentage of the maximal contraction induced by histamine.
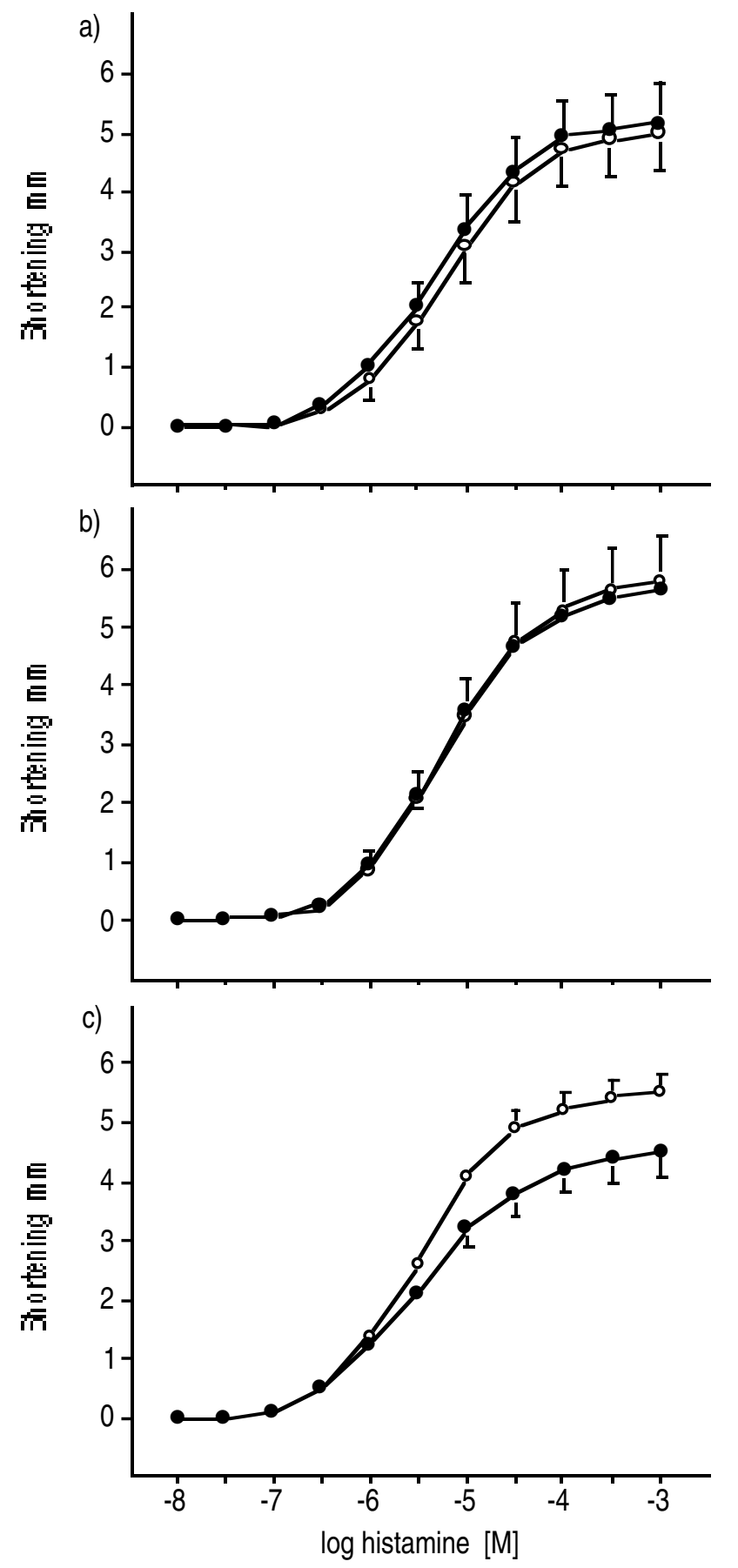

Fig. 3. - Histamine concentration-response curves of bovine tracheal smooth muscle strips. Effects of: a) $1 \mathrm{mM} \mathrm{L-arg}(\mathrm{n}=5)$; b) 120 $\mu \mathrm{M}$ L-NAME $(\mathrm{n}=5)$; and c) $120 \mu \mathrm{M}$ L-NMMA $(\mathrm{n}=6)$. - - - - control group; - - : treated group. Results are presented as mean \pm SEM. L-arg: L-arginine; L-NAME: $\mathrm{N}^{\mathrm{G}}$-nitro-L-arginine methyl ester; LNMMA: $\mathrm{NG}^{\mathrm{G}}$-monomethyl L-arginine.

Sensitivity of bovine tracheal smooth muscle to exogenous $N O$

L-Arg $(1 \mathrm{mM})$ did not relax intact precontracted strips $(n=5)$. However, SNAP reversed the contraction in a concentration-dependent fashion (fig. 4). SNAP (100 $\mu \mathrm{M})$ decreased the muscle shortening by $91 \%$ from $5.3 \pm 0.7$ to $0.5 \pm 1.0 \mathrm{~mm}(\mathrm{p}<0.01 ; \mathrm{n}=5)$. From this concentration of SNAP, $58.4 \pm 1.3 \mathrm{nmol} \cdot \mathrm{mL}^{-1} \mathrm{NO}$ is released 
Table 2. - Parameters derived from histamine concentration-response curves of bovine isolated tracheal smooth muscle strips, preincubated with L-arginine and its analogues for $25 \mathrm{~min}$

\begin{tabular}{|c|c|c|}
\hline & $\begin{array}{l}\text { Control } \\
\text { group }\end{array}$ & $\begin{array}{l}\text { Treated } \\
\text { group }\end{array}$ \\
\hline \multicolumn{3}{|l|}{ L-Arg (1 mM) } \\
\hline Basal displacement $\mathrm{mm}^{\S}$ & $0.0 \pm 0.1$ & $0.0 \pm 0.1$ \\
\hline Histamine $\mathrm{pD}_{2}$ & $5.2 \pm 0.1$ & $5.3 \pm 0.1$ \\
\hline Histamine $E \max \mathrm{mm}$ & $5.0 \pm 0.6$ & $5.2 \pm 0.6$ \\
\hline Aminophylline relaxation $\%$ & $108 \pm 4$ & $112 \pm 5$ \\
\hline Strips n & 5 & 5 \\
\hline \multicolumn{3}{|l|}{ L-NAME $(120 \mu \mathrm{M})$} \\
\hline Basal displacement $\mathrm{mm}^{\S}$ & $-0.2 \pm 0.0$ & $-0.1 \pm 0.1$ \\
\hline Histamine $\mathrm{pD}_{2}$ & $5.2 \pm 0.2$ & $5.3 \pm 0.1$ \\
\hline Histamine $E \max \mathrm{mm}$ & $5.8 \pm 0.7$ & $5.6 \pm 0.2$ \\
\hline Aminophylline relaxation $\%$ & $103 \pm 11$ & $104 \pm 4$ \\
\hline Strips $n$ & 5 & 5 \\
\hline \multicolumn{3}{|l|}{ L-NMMA (120 $\mu \mathrm{M})$} \\
\hline Basal displacement $\mathrm{mm}^{\S}$ & $0.1 \pm 0.2$ & $1.1 \pm 0.3^{*}$ \\
\hline Histamine $\mathrm{pD}_{2}$ & $5.5 \pm 0.1$ & $5.5 \pm 0.1$ \\
\hline Histamine $E$ max $\mathrm{mm}$ & $5.5 \pm 0.3$ & $4.5 \pm 0.4$ \\
\hline Aminophylline relaxation $\%$ & ND & ND \\
\hline Strips n & 6 & 6 \\
\hline
\end{tabular}

Results are presented as mean \pm SEM. $\S$ : changed muscle length during the preincubation time; $\$$ : relaxation achieved with $20 \mathrm{mM}$ of aminophylline and expressed as percentage of the maximal contraction induced by histamine. ND: not determined. For further definitions see legends to table 1 and figure 3. *: $\mathrm{p}<0.05$, significantly different from the corresponding control group as tested by Bonferroni's t-test.

$(n=4)$. The time control preparations, treated only with histamine, relaxed spontaneously by $8.0 \pm 1.5 \%$ over 30 $\min (n=5)$.

\section{Release of $\mathrm{NO}$ and $\mathrm{PGE}$ from epithelium}

Upon stimulation with $0.1 \mu \mathrm{M}$ of histamine, NO release was enhanced in the control epithelium 3.2 fold,

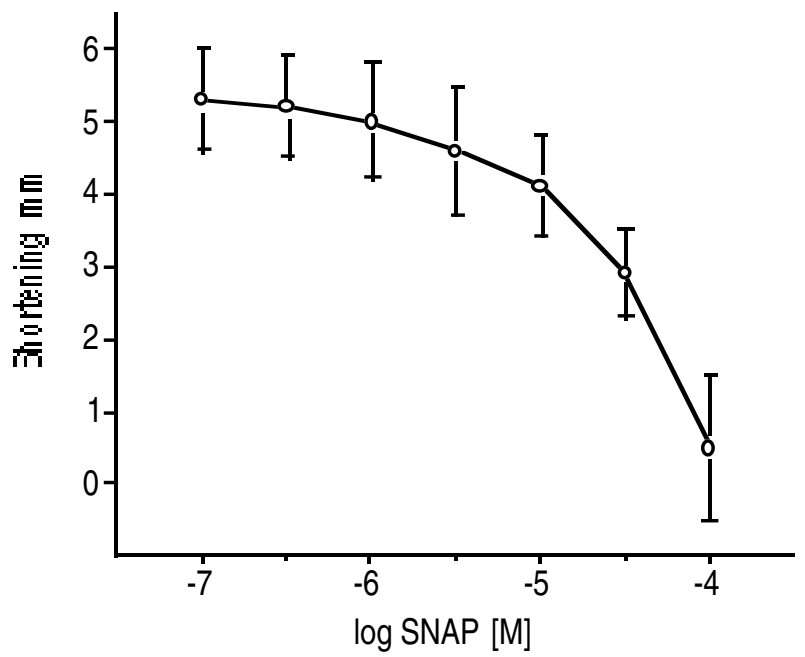

Fig. 4. - Concentration-response curve of bovine tracheal smooth muscle strips with SNAP (a nitric oxide donor); the tissues were first precontracted with $1 \mathrm{mM}$ of histamine. SNAP $(100 \mu \mathrm{M})$ reversed $91 \%$ of the contraction induced by histamine, suggesting sensitivity of the muscle strips to exogenous nitric oxide $(\mathrm{p}<0.01 ; n=5)$. Results are presented as mean \pm SEM. SNAP: S-nitroso-N-acetyl-penicillamine. from $2.39 \pm 0.38$ to $7.71 \pm 1.76 \mathrm{pmol} \cdot \mathrm{mg}^{-1}(\mathrm{p}<0.01 ; \mathrm{n}=4)$ (fig. 5a). Incubation with L-arg enhanced the basal NO release two fold. In this group, the release of NO after application of histamine was enhanced 4.4 fold from
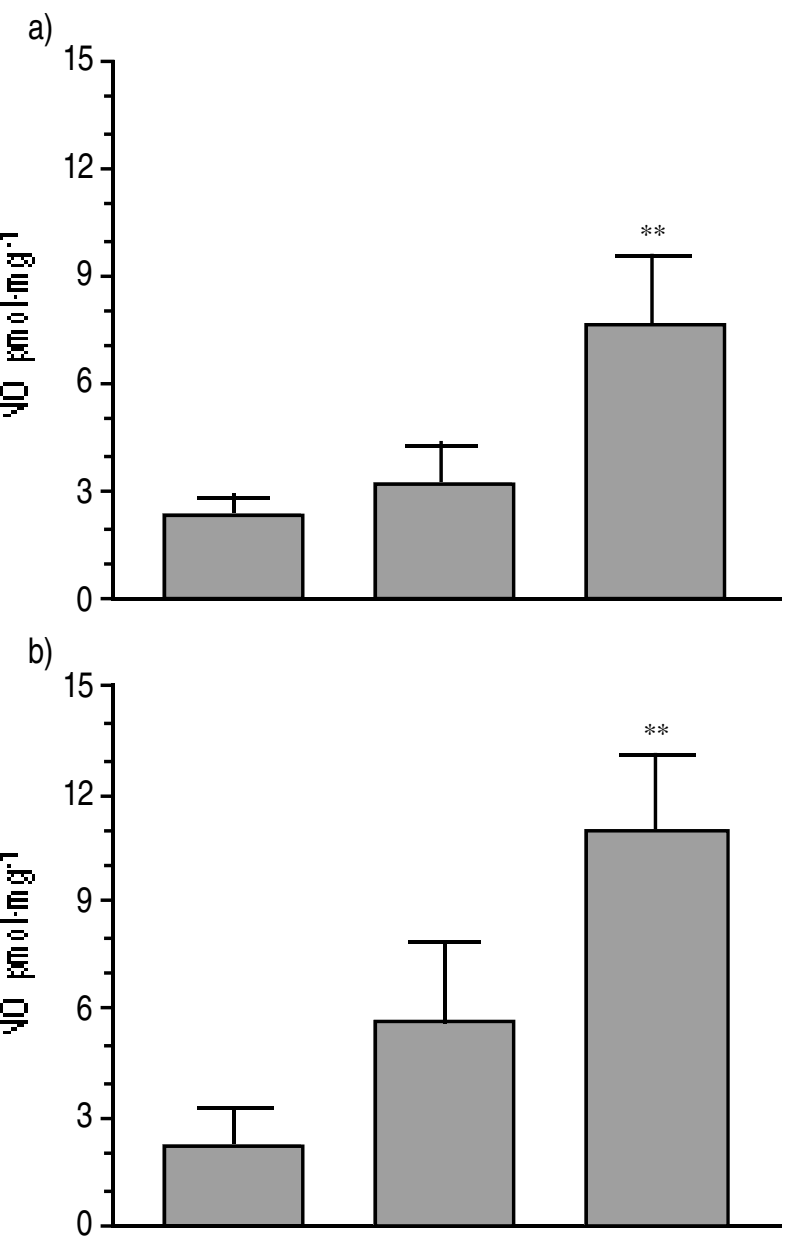

c)

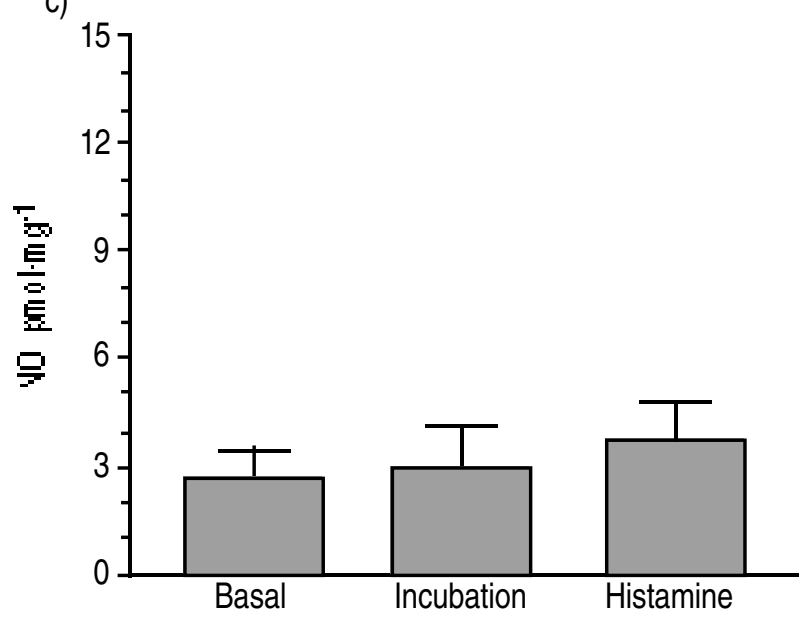

Fig. 5. - Release of nitric oxide (NO) from the isolated epithelial layer of bovine trachea. Accumulation of nitrite in the buffer was detected as an indication of NO production. The tissues were incubated for 25 min with: a) the control solution ( $=4)$; b) $1 \mathrm{mM} \mathrm{L-arg}$ $(n=4)$; or c) $120 \mu \mathrm{M}$ L-NMMA $(n=4)$. L-arg increased the basal NO release slightly. Histamine $(0.1 \mu \mathrm{M})$ increased the release of NO significantly except in the group which was treated with L-NMMA. **: $\mathrm{p}<0.01$, compared to the corresponding basal level. Results are presented as mean \pm SEM. For definitions see legend to figure 3. 


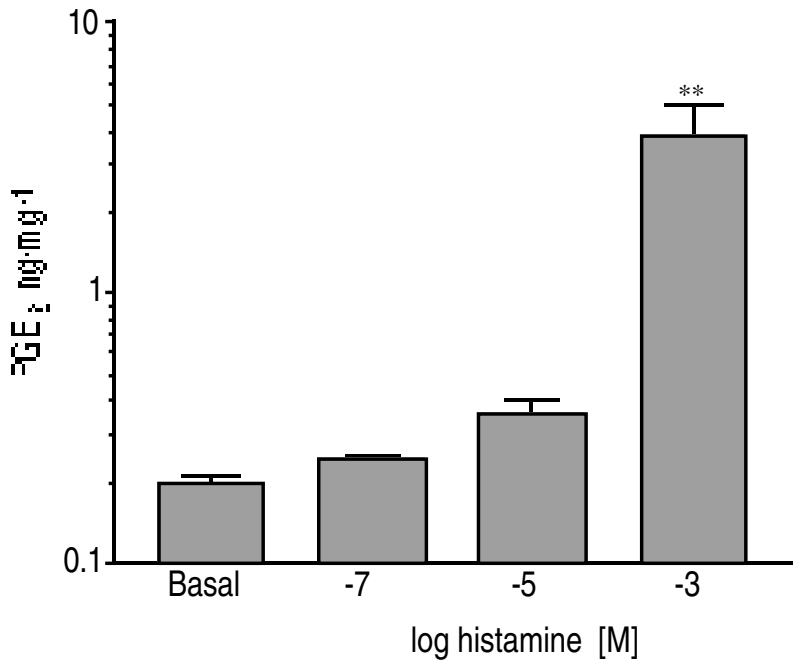

Fig. 6. - Release of prostaglandin $\mathrm{E}_{2}\left(\mathrm{PGE}_{2}\right)$ from the epithelial layer of bovine isolated trachea was enhanced by histamine $(n=4)$. **: $\mathrm{p}<0.01$, compared to the basal level. Results are presented as mean \pm SEM.

$2.16 \pm 1.11$ (before incubation) to $10.96 \pm 2.12 \mathrm{pmol} \cdot \mathrm{mg}^{-1}$ $(\mathrm{p}<0.01 ; \mathrm{n}=4)$ (fig. $5 \mathrm{~b})$. After treatment with L-NMMA, the effect of histamine on NO release was completely inhibited; NO levels before incubation and after histamine treatment were $2.72 \pm 0.74$ and $3.71 \pm 0.99 \mathrm{pmol} \cdot \mathrm{mg}^{-1}$, respectively $(\mathrm{n}=4)$ (fig. $5 \mathrm{c}$ ). Application of higher concentrations of histamine $(10 \mu \mathrm{M}$ and $1 \mathrm{mM})$ did not increase the release of NO any further, irrespective of the treatment procedure.

Nonstimulated tracheal epithelium released $0.20 \pm 0.1$ $\mathrm{ng} \cdot \mathrm{mg}^{-1} \mathrm{PGE}_{2}$; this amount was not significantly changed after addition of 0.1 and $10 \mu \mathrm{M}$ histamine. However, $\mathrm{PGE}_{2}$ release from epithelium was enhanced after addition of $1 \mathrm{mM}$ histamine to $3.80 \pm 1.08 \mathrm{ng} \cdot \mathrm{mg}^{-1}(\mathrm{p}<0.01$; $\mathrm{n}=4$ ) (fig. 6).

\section{Discussion}

This study showed that under the present experimental conditions, histamine responsiveness of bovine tracheal smooth muscle was not modulated by removal of the epithelium or L-arg and L-NAME, whereas L-NMMA decreased the maximal response. The SNAP-induced relaxation of the muscle strips, however, indicated that bovine trachea was sensitive to exogenous NO in modulating airway tone in this species. In addition, it was shown that basal levels of $\mathrm{NO}$ and $\mathrm{PGE}_{2}$ are released by the epithelial layer and are enhanced after stimulation with histamine.

In the guinea-pig trachea, the epithelial layer releases NO when stimulated by histamine or potassium chloride $[18,22]$. However, until now, there has been no direct evidence for the formation of $\mathrm{NO}$ in bovine trachea. Histamine-induced contractions of bovine tracheal smooth muscle are correlated with increased cGMP levels [23]. Accumulation of cGMP after exposure of this preparation to carbachol is believed to be mediated by a substance similar to endothelium-derived relaxing factor (EDRF), i.e. NO [24]. Endothelium-derived and exogenous NO can relax bovine tracheal smooth muscle in vitro $[25,26]$. In addition, unstimulated, cultured bovine bronchial epithelial cells have been reported to metabolize L-arginine to L-citrulline [27], suggesting a basal release of NO.

In the present study, more direct evidence for the basal release of NO from bovine tracheal epithelium was found by measuring the radical itself. Moreover, it was shown that: 1) the basal release of $\mathrm{NO}$ can be increased by addition of L-arg; 2) histamine significantly increases the release of $\mathrm{NO} ; 3$ ) a concentration of histamine as low as $0.1 \mu \mathrm{M}$ may be sufficient for maximal activation of the constitutive NO synthase in this preparation, as no additional effect was observed with higher concentrations of the agonist; and 4) the effect of histamine was completely inhibited by L-NMMA. These results and the findings of others indicate a role for $\mathrm{NO}$ and cGMP in bovine airways. Besides NO, formation of $\mathrm{PGE}_{2}$ in the epithelial cells from guinea-pigs and bovine airways has been demonstrated $[2,4,7]$. We also found that $\mathrm{PGE}_{2}$ is released from bovine tracheal epithelium and that it is enhanced by higher amounts of histamine. $\mathrm{NO}$ and $\mathrm{PGE}_{2}$ may act as epithelium-derived inhibitory factors (EpDIFs) and, therefore, suggest a role for epithelium in modulating bovine tracheal responsiveness.

Removal of epithelium did not influence the tracheal responsiveness to histamine. Each muscle strip prepared by the method used in the present study was covered by approximately $8.4 \mathrm{mg}$ of its adherent epithelium [21]. The maximal concentrations of the epithelium-derived $\mathrm{NO}$ and $\mathrm{PGE}_{2}$ in a $12 \mathrm{~mL}$ organ bath, after stimulation by histamine, would be 5.4 and $7.4 \mathrm{nM}$, respectively. NO has to be applied in micromolar concentrations to induce bovine tracheal relaxation, i.e. 1,000 times more than released from the epithelium [25]. It should be noted that, in this study, the accumulation of nitrite in the buffer has been considered as an indication of NO release. It is possible that NO, to some extent, is also converted to other substances. The $\mathrm{PGE}_{2}$ concentrations may also be insufficient; at least a 10 fold higher concentration is required to initiate relaxation in the guinea-pig perfused trachea [28]. Therefore, the amounts of EpDIF released by the epithelial layer of bovine trachea are not sufficient to exert a modulatory effect on tracheal contractions.

As shown in figure 1, an extensive volume of lamina propria is present between the epithelium and smooth muscle of bovine trachea. Compared to guinea-pig trachea, the distance between the epithelial and smooth muscle cells of bovine trachea is four fold larger. Therefore, chemicals released by epithelial cells are likely to reach bovine tracheal smooth muscle with more difficulty. Finally, stimulated bovine trachea also releases contractile metabolites of arachidonic acid, e.g. prostaglandin $\mathrm{F}_{2 \alpha}\left(\mathrm{PGF}_{2 \alpha}\right)$ [4], that may counteract the relaxing effects of the EpDIFs. Interestingly, it was shown that NO and $\mathrm{PGE}_{2}$ are released upon stimulation with lower and higher concentrations of histamine, respectively. This may suggest that different inhibitory mechanisms can be involved during different pathophysiological conditions in the airways.

It is difficult to explain why BARNES et al. [6] found that removal of epithelium from bovine tracheal smooth muscle enhanced isometric contractions to histamine. This could be a consequence of the different methods used to study responsiveness of tracheal preparations, 
i.e. isometric versus isotonic. However, obtaining similar results with either method in the present study eliminated such a possibility. There is evidence in the literature showing that removal of epithelium did not influence guinea-pig tracheal sensitivity to histamine [29], and methacholine-induced contraction of rat trachea [30]. This controversy may depend upon strain or species differences. In addition, different experimental conditions, such as muscle pretension versus the volume of muscle strips, might also be involved. Airway epithelium may act as a barrier to protect against agonists and noxious chemicals [31]. However, this role may be appreciated only when perfused tracheal or bronchial tubes are exposed to drugs from the mucosal side but not in the model used in our study. A strip of tracheal smooth muscle is covered by epithelium only from one side and easily exposed to chemicals from the remaining three sides; this excludes the barrier function of the epithelium.

A study from our group [19] has revealed that NOS inhibitors induce airway hyperresponsiveness to histamine in the guinea-pig perfused trachea. However, the present study showed that preincubation of bovine tracheal smooth muscle with L-arg and L-NAME did not modulate the responsiveness to histamine. The difference in the preparations may be one reason for this discrepancy; guinea-pig tracheas were perfused and exposed to the drugs from the mucosal side, whereas bovine tracheal strips were exposed to the drugs from all sides. This means that the epithelium may not have a protective role in bovine tracheal smooth muscle strips. On the other hand, it could just result from an interspecies difference, and NO may have a less crucial role in airway responsiveness in cattle than in guinea-pigs. L-NMMA caused a slight muscle contraction by itself This effect was not NO-dependent because L-arg-treated preparations also developed a comparable response to L-NMMA. The mechanism of this contraction remains to be discovered. The contractile effect of L-NMMA could be a reason for the decrease in the Emax of histamine that was observed in L-NMMA-treated strips. Indeed, the sum of contractions induced by L-NMMA and histamine was approximately equal to the contraction induced by histamine in the control group.

Although we did not observe any influence by NO originating from the airway on bovine tracheal responsiveness, complete relaxation of the muscle strips by the NO-producing agent SNAP confirms the sensitivity of the tissue to NO in this species. There is circumstantial evidence that NO released from pulmonary vessels may be impaired in patients with chronic obstructive pulmonary disease (COPD) [32]. Therefore, it may be interesting to investigate the role of endogenous NO from sources other than the airway epithelium or tracheal smooth muscle (e.g. the vasculature) on airway reactivity.

In conclusion, the release of nitric oxide and prostaglandin $E_{2}$ from bovine tracheal epithelial layer is increased upon stimulation by histamine. However, the amounts of mediators released are not sufficient to modulate the contractility of the tracheal smooth muscle to histamine. The sensitivity of tracheal smooth muscle to exogenous nitric oxide demonstrates the existence of the nitric oxide/ cyclic guanosine monophosphate pathway in the airways of this species.
Acknowledgements: The authors would like to thank R.B.R. Muijsers for his technical assistance in $\mathrm{PGE}_{2}$ radioimmunoassay.

\section{References}

1. Holroyde MC. The influence of epithelium on the responsiveness of guinea-pig isolated trachea. Br J Pharmacol 1986; 87: 501-507.

2. Nijkamp FP, Folkerts G. Reversal of arachidonic acidinduced guinea-pig tracheal relaxation into contraction after epithelium removal. Eur J Pharmacol 1987; 131: 315-316.

3. Munakata M, Huang I, Mitzner W, Menkes H. Protective role of epithelium in the guinea-pig airway. $J$ Appl Physiol 1989; 66: 1547-1552.

4. Doupnik CA, Leikauf GD. Acrolein stimulates eicosanoid release from bovine airway epithelial cells. Am J Physiol 1990; 259: L222-L229.

5. Farmer SG, Hay DWP. The Airway Epithelium: Physiology, Pathophysiology and Pharmacology. New York, Marcel Dekker, 1991.

6. Barnes PJ, Cuss FM, Palmer JB. The effect of airway epithelium on smooth muscle contractility in bovine trachea. Br J Pharmacol 1985; 86: 685-691.

7. Folkerts G, Engels F, Nijkamp FP. Endotoxin-induced hyperreactivity of the guinea-pig isolated trachea coincides with decreased prostaglandin $\mathrm{E}_{2}$ production by the epithelial layer. Br J Pharmacol 1989; 96: 388-394.

8. Fedan JS, Nutt ME, Frazer DG. Reactivity of guineapig isolated trachea to methacholine, histamine and isopretrenol applied serosally versus mucosally. Eur Pharmacol 1990; 190: 337-345.

9. Barnes PJ, Belvisi MG. Nitric oxide and lung disease. Thorax 1993; 48: 1034-1043.

10. Nijkamp FP, Folkerts G. Nitric oxide and bronchial reactivity. Clin Exp Allergy 1994; 24: 905-914.

11. Moncada S, Palmer RMJ, Higgs EA. Nitric oxide: physiology, pathophysiology and pharmacology. Pharmacol Rev 1991; 43: 109-142.

12. Belvisi MG, Stretton CD, Barnes PG. Nitric oxide as an endogenous modulator of cholinergic neurotransmission in guinea-pig airways. Eur J Pharmacol 1991; 198: 219-221.

13. Li CG, Rand MJ. Evidence that part of the NANC relaxant response of guinea-pig trachea to electrical field stimulation is mediated by nitric oxide. Br J Pharmacol 1991; 102: 91-94.

14. Belvisi MG, Stretton CD, Yacoub M, Barnes PJ. Nitric oxide is the endogenous neurotransmitter of bronchodilator nerves in humans. Eur J Pharmacol 1992; 210: 221-222.

15. Kannan MS, Johnson DE. Nitric oxide mediates the neural nonadrenergic, noncholinergic relaxation of pig tracheal smooth muscle. Am J Physiol 1992; 262: L511L514.

16. Bai TR, Bramley AM. Effect of an inhibitor of NO synthase on neural relaxation of human bronchi. Am J Physiol 1993; 264: L425-L430.

17. Fisher JT, Anderson JW, Waldron MA. Nonadrenergic noncholinergic neurotransmitter of feline trachealis VIP or nitric oxide. J Appl Physiol 1993; 74: 31-39.

18. Folkerts G, van der Linde H, Nijkamp FP. Virus-induced airway hyperresponsiveness in guinea-pigs is related to a deficiency in nitric oxide. J Clin Invest 1995; 95: 26-30.

19. Nijkamp FP, van der Linde HJ, Folkerts G. Nitric oxide 
synthesis inhibitors induce airway hyperresponsiveness in the guinea-pig in vivo and in vitro; role of the epithelium. Am Rev Respir Dis 1993; 148: 727-734.

20. Sadeghi Hashjin G, Folkerts G, Henricks PAJ, Nijkamp FP. Pharmacological modulation of cyclic GMP and guinea-pig tracheal responsiveness in vitro. Am J Respir Crit Care Med 1994; 149: A766.

21. Sadeghi Hashjin G, Henricks PAJ, Folkerts G, Nijkamp FP. Preparation of bovine tracheal smooth muscle for in vitro pharmacological studies. J Pharmacol Toxicol Meth 1995; 34: 103-108.

22. Folkerts G, van der Linde HJ, Verheyen AKCP, Nijkamp FP. Endogenous nitric oxide modulation of potassium-induced changes in guinea-pig airway tone. $\mathrm{Br} \mathrm{J}$ Pharmacol 1995; 115: 1194-1198.

23. Katsuki S, Murad F. Regulation of adenosine cyclic 3',5'-monophosphate and guanosine cyclic 3',5'-monophosphate levels and contractility in bovine tracheal smooth muscle. Mol Pharmacol 1977; 13: 330-341.

24. Sheng H, Ishii K, Murad F. Generation of an endothelium-derived relaxing factor-like substance in bovine tracheal smooth muscle. Am J Physiol 1991; 260: L489-L493.

25. Buga GM, Gold ME, Wood KS, Chaudhuri G, Ignarro IJ. Endothelium-derived nitric oxide relaxes nonvascular smooth muscle. Eur J Pharmacol 1989; 161: 61-72.

26. Gruetter CA, Childers CE, Bosserman MK, Lemke SM, Ball JG, Valentovic MA. Comparison of relaxation induced by glyceryl trinitrate, isosorbide dinitrate and sodium nitroprusside in bovine airways. Am Rev Respir Dis 1989; 139: 1192-1197.

27. Robbins RA, Hamel FG, Floreani AA, et al. Bovine bronchial epithelial cells metabolize L-arginine to L-citrulline: possible role of nitric oxide synthase. Life Sci 1993; 52: 709-716.

28. Folkerts G, van der Linde HJ, Nijkamp FP. Guinea-pig tracheal hyperresponsiveness induced by nitric oxide synthesis inhibition is mediated by 5-lipoxygenase metabolites. Am J Respir Crit Care Med 1995; 151: A832.

29. Thompson, DC, Wells JL, Altiere RJ, Diamond L. The effect of epithelium removal on nonadrenergic, noncholinergic inhibitory responses in the isolated central airways of the cat and guinea-pig. Eur J Pharmacol 1988; 145: 231-237.

30. Doelman CJ, Oosterom WC, Bast A. Regulation of sympathetic and parasympathetic receptor responses in the rat trachea by epithelium: influence of mechanical and chemical removal of epithelium. J Pharm Pharmacol 1990; 42: 831-836.

31. Mitchell HW, Willet KE, Sparrow MP. Perfused bronchial segment and bronchial strip: narrowing $v s$ isometric force by mediators. J Appl Physiol 1989; 66: 2704-2709.

32. Dinh-Xuan AT, Higenbottam TW, Clelland CA, et al. Impairment of endothelium-dependent pulmonary artery relaxation in chronic obstructive lung disease. $N$ Engl J Med 1991; 324: 1539-1547. 